\title{
O cuidado psicológico ao médico em reprodução assistida: um enquadre diferenciado'
}

\author{
Psychological care for the human reproduction \\ physician: a distinct clinical setting
}

\author{
Keith Laura MIRANDA ${ }^{2}$ \\ Paulo Cesar SERAFINI ${ }^{2}$ \\ Edmund Chada BARACAT $^{2}$
}

\begin{abstract}
Resumo
Profissionais da área da saúde entram em contato com o sofrimento humano mesmo quando não trabalham diretamente no campo da Psicologia. Este estudo baseou-se no referencial da psicanálise com vistas a compreender os aspectos do sofrimento humano que emerge para os médicos no exercício da reprodução assistida, e a importância do estudo do imaginário coletivo sobre situações de difícil manejo em suas clínicas. Participaram vinte e dois médicos que atuam em hospitais e clínicas do estado de São Paulo em âmbitos público e privado, independentemente de sexo, idade e tempo de formação. Foi utilizado o procedimento desenhos-estórias com tema, compreendido como procedimento dialógico. A entrevista caracterizou-se como uma situação especial de comunicação e expressão das emoções geradas nos atendimentos relacionados à temática proposta. Constatou-se a necessidade de proposição de espaços facilitadores da expressão emocional, que promovem a continência do sofrimento humano e a ocorrência de experiências reflexivo-vivenciais transformadoras do real.
\end{abstract}

Unitermos: Atenção psicológica clínica. Pesquisa psicanalítica. Reprodução assistida. Sofrimento no trabalho.

\begin{abstract}
Health professionals have to deal with human suffering, even if they don't deal directly with interventions in the psychology area. This study was based on Psychoanalysis, with the aim of understanding the aspects of human suffering which emerge with doctors in the exercise of their work with assisted human reproduction, considering the collective model concerning the difficult situations that they have to deal with in their clinics. Twenty-two doctors working in hospitals and clinics in the state of São Paulo, in both private and public facilities, volunteered to participate, ignoring sex, age and time since graduation. The Drawing and Storytelling thematic was used as the dialogical procedure. The interview was characterized as a special situation with the expression and communication of emotions generated in sessions related to the proposed theme. It was found that there was a need for the proposition of facilitating spaces for emotional expression, promoting the containment of human suffering and the occurrence of the transforming life reflection experiences of reality.
\end{abstract}

Uniterms: Clinical psychological care. Psychoanalytic research. Human reproduction. Suffering work.

$\boldsymbol{\nabla \nabla v \nabla}$

- Artigo elaborado a partir da dissertação de K.L. MIRANDA, intitulada "E do médico, quem cuida? Enquadre diferenciado no cuidado psicológico ao médico especialista em reprodução assistida". Faculdade de Medicina da Universidade de São Paulo, 2011.

2 Universidade de São Paulo, Faculdade de Medicina, Divisão e Hospital das Clínicas, Clínica Ginecológica. Av. Arnaldo, 455, Cerqueira César, 01246-903, São Paulo, SP, Brasil. Correspondência para/Correspondence to: K.L. MIRANDA. E-mail: <psicomoeller@gmail.com>. 
Profissionais das mais diversas áreas da saúde diariamente entram em contato com o sofrimento humano, mesmo quando não lidam diretamente com intervenções no campo da Psicologia. Pode-se supor que trabalhar em um ambiente como um hospital ou uma clínica que sirva de porta de entrada para a realização de procedimentos invasivos faz com que o profissional, muitas vezes, depare-se com suas próprias questões, angústias, que podem vir afetar sua atuação profissional. Fala-se muito do sofrimento dos pacientes em inúmeras pesquisas em psicologia e sobre intervenções que parecem interessantes para contribuir ao desenvolvimento emocional desses pacientes. No que se refere ao cuidado do paciente, esse fato é extremamente importante, mas eis que surge uma pergunta: e do médico, quem cuida?

Durante o Programa de Aprimoramento Profissional em Psicologia em Hospital Geral, realizado na Divisão e Clínica Ginecológica no Centro de Reprodução Humana do Instituto Central do Hospital das Clínicas da Faculdade de Medicina da Universidade de São Paulo (CRH-ICHC-FMUSP), perceberam-se as angústias geradas pelas diversas situações que se apresentavam no âmbito da relação médico-paciente.

Foi possível observar expressões abatidas após um exame de gravidez negativo ou após uma intervenção cirúrgica cujo resultado não havia sido exatamente o esperado. Muitas vezes, surgiam discussões que fugiam à técnica que estava sendo estudada. Os médicos, muitas vezes, compartilhavam situações difíceis em sua prática profissional e seus sentimentos, porém existia uma tendência de defenderem-se dos assuntos por meio de piadas ou por meio de tentativas de racionalização dos sentimentos e de busca por padrões de conduta médica. Essas e outras situações semelhantes deixavam claro que existia uma dificuldade em trabalhar questões emocionais que apareciam durante o fazer profissional do médico.

Certamente, deve-se prestar atenção às questões dos pacientes, pois sabemos que a experiência de tornar-se pai ou mãe pode gerar diversos tipos de questionamentos, expectativas, conflitos e sintomas não só em pais que concebem de maneira natural, mas também em casais que concebem por meio da Reprodução Assistida (RA), conforme a literatura tem demons72 trado (Gorayeb, Borsari, Gomes, Romão \& Shuhama, 2009;
Piccinini, Devandowski, Gomes, Lindenmeyer \& Lopes, 2009; Silva \& Piccinini, 2007; Lechner, Bolman van Daler, 2006; Trindade \& Emuno, 2002; Verhaak et al. 2007). Entretanto, com a experiência no CRH-ICHC-FMUSP, foi possível perceber que, além das questões dos pacientes, parecia existir algo que precisaria ser abordado: a angústia do médico. Na maioria das vezes, esse assunto não era abordado, e quando abordado, a forma era pouco produtiva. Foi possível perceber que existia um sofrimento, uma demanda muda, que apontou para a reflexão de que talvez fosse interessante pensar em exercer algum tipo de trabalho que pudesse contribuir para a saúde psicológica de tais profissionais; para isso, era necessária uma investigação que trouxesse informações a respeito da vivência emocional daqueles profissionais quanto ao exercício de sua profissão.

Ultimamente, têm sido feitos questionamentos a respeito da formação do médico. Segundo alguns estudos, o exercício da medicina tem se apresentado apegado a uma prática mais cartesiana do que holística, um ensino memorístico disciplinar ao invés de um saber global. Além disso, existiria uma prática pedagógica que favoreceria tal posicionamento cientificista, pela instalação de um modelo de assistência distante e impessoal (Bastos \& Proença, 2000; Rodriguez, Neto \& Behrens, 2004).

Rocco (1992) enfatiza que, já durante o curso de graduação, fica claro que os estudantes de medicina aprendem que o trabalho do médico deve estar acompanhado por um controle quase que absoluto sobre suas emoções. Uma vez que convive com situações de dor, miséria e até morte em seu ofício, esse contato constante e muito próximo com o sofrimento humano certamente afeta o fazer profissional e pode prejudicar seu julgamento e suas intervenções. Nesse sentido, uma das alternativas consiste na busca de ajuda especializada, mas também aponta para mecanismos de controle da situação por meio da defesa e do distanciamento do paciente, buscando-se a racionalidade, a explicação pela via da técnica no organicismo (Ramos-Cerqueira \& Lima, 2002).

Para incrementar a discussão, vale fazer uso de certo conhecimento psicológico, especificamente da pesquisa por imaginários coletivos (Aiello-Vaisberg, 1999), para entender, sob outro ponto de vista, a situação 
médico-paciente. A proposta por enquadres diferenciados, psicanaliticamente orientados, a serviço da pesquisa-intervenção dos imaginários coletivos, desenvolvida por Aiello-Vaisberg (1999; 2004), parte da compreensão das condutas humanas de forma ampliada, e abrange os componentes consciente e inconsciente, bem como aspectos sociais, compreendidos aqui não como elementos que podem se separar das motivações individuais, mas, essencialmente, concebendo o ser humano como um conjunto ambiente-indivíduo, indissociável. Dessa forma, entende-se que as ações humanas estão fortemente ancoradas nas apreensões que os seres humanos fazem do mundo, não na realidade objetivamente percebida. Éimportante esse conhecimento para ampliar tanto a compreensão acerca das dificuldades por que passam médicos e pacientes, mas também para propor medidas de intervenção.

Micelli-Baptista (2003) estudou a solicitação da interconsulta médico-psicológica por residentes de medicina, por meio do desenhos-estórias com tema utilizados como procedimento apresentativo-expressivo (Aiello-Vaisberg, 1999). O estudo deu subsídios e a autora concluiu que o sujeito coletivo de um determinado grupo de residentes de medicina de um hospital universitário apresentou medo e dúvida em relação às questões humanas que fogem ao conhecimento e à tecnologia médico-científica. Há o sentimento de ter que dar conta, de modo onipotente, de todas as questões que surgirem em relação ao paciente; a idealização de que se deve dominar qualquer dificuldade e trazer sempre a solução, a cura ou interrupção de qualquer sofrimento; a percepção de que o papel de doente não está restrito ao paciente, podendo ser o de qualquer pessoa, inclusive o seu próprio. Esse grupo pôde também perceber que, em alguns momentos, poderia existir extrema sensibilidade e atenção à experiência de sofrimento emocional relativa a seu paciente, bem como poderia existir a abertura para novas situações, pois ao convidá-los a participar de um enquadre diferenciado, como o procedimento desenhos-estórias com tema, a ideia foi bem recebida. Chamou MicelliBaptista (2003) as entrevistas de psicoprofiláticas, já que foi ao encontro dos residentes mediante sua percepção da necessidade de oferecer-Ihes auxílio emocional.

O enquadre diferenciado no qual se deu a pesquisa de Micelli-Baptista (2003) traz a possibilidade de se pensar em práticas diferenciadas na pesquisa psicanalítica. Winnicott (1962/1983), abordando o tratamento psicanalítico, coloca que ele fazia análise em seus pacientes quando eles precisavam, mas, se o paciente não necessitava de análise, fazia alguma outra coisa. É importante deixar claro que o fazer alguma outra coisa não é sinônimo de fugir do rigor psicanalítico, mas significa que, em determinadas situações, o psicanalista pode lançar mão de seu saber técnico para realizar alguma outra coisa apropriada para a ocasião (Winnicott 1983).

Winnicott (1984) apresentou, em seu livro "Consultas Terapêuticas em Psiquiatria Infantil", uma nova proposta de enquadre clínico - as consultas terapêuticas -, conceitualizando que a primeira consulta pode ser terapêutica por si só (Abram, 1996). Essa compreensão acerca dos alcances - notadamente ampliados quando se refere ao enquadre psicanalítico padrão - da atuação do psicanalista parece incentivadora à reflexão e à busca por novas modalidades de atendimento psicoterapêutico/psicoprofilático, bem como pode apontar novas modalidades de estratégias metodológicas para a pesquisa.

Nesse sentido, compreende-se que o psicanalista, quando em seu ofício, pode apresentar possibilidades de cuidado emocional para além do acompanhamento a longo prazo, com objetivos educativos ou decifradores (Machado \& Aiello-Vaisberg 2003). Dependendo das condições relativas à situação apresentada, um único encontro poderia ser transformador, aliviando as angústias dos pacientes e fazendo com que retomem suas vidas de forma mais saudável e mais integrada. Está implícita na obra winnicottiana e nas proposições de autores pós-winnicottianos (Aiello-Vaisberg, 2004; Ambrosio, 2005) a concepção de intervenção psicanalítica não interpretativa, ancorada no conceito de sustentação emocional, holding. Nesse sentido, pretende-se realizar algo distante de procedimentos que visem ao autoconhecimento intelectual, a racionalização, mas instrumentos que favoreçam a superação de dissociações, a integração de sentimentos, intervenções que aproximem a pessoa do sentimento de ser si mesma.

Considerando as bases epistemológicas e o conceito de psicoprofilaxia de Bleger (1984) e as contribuições do pensamento do psicanalista Winnicott (1984), desenvolveu-se um projeto de mestrado cujo objetivo 
era identificar as situações de difícil manejo na relação médico-paciente. Semelhante ao que relata Mencarelli e Aiello-Vaisberg (2005), a pesquisa também requeria da psicanalista que ela fosse capaz de criar alternativas para que o encontro, na ocasião da pesquisa, pudesse beneficiar os participantes por meio de um instrumento dialógico capaz de proporcionar expressão emocional.

Pretendeu-se estudar e compreender, por meio do caráter da entrevista psicoprofilática (Bleger, 1984), aspectos do sofrimento humano que emergem no dia a dia dos médicos no exercício da reprodução assistida, considerando o estudo do imaginário coletivo sobre situações de difícil manejo para estudar o sujeito coletivo médico em âmbito coletivo de manifestação humana (Aiello-Vaisberg, 1995).

\section{Método}

\section{Participantes}

O estudo foi aprovado pelo Comitê de Ética para Análise de Projetos de Pesquisa (CAPPesq) da Diretoria Clínica do Hospital das Clínicas e da Faculdade de Medicina da Universidade de São Paulo, protocolo no 0950/08, em 19/11/2008, e todos os participantes assinaram um termo de consentimento livre e esclarecido antes de sua inclusão na amostra.

Foram convidados médicos que atuam em reprodução assistida em hospitais e clínicas do estado de São Paulo em âmbitos público e privado, independentemente de sexo e tempo de formação. Foram entrevistados vinte e dois médicos com idades entre 29 e 58 anos, de ambos os sexos.

\section{Instrumentos}

Foram utilizadas como instrumento entrevistas individuais para abordagem do sujeito coletivo. Fez-se uso do procedimento desenhos-estórias com tema, compreendido como procedimento dialógico e não como um teste projetivo, seguindo-se a proposta de procedimento apresentativo-expressivo (AielloVaisberg, Corrêa \& Ambrosio, 2005).

O procedimento desenhos-estórias com tema foi escolhido por promover uma forma especial de diálogo, de ludicidade ao encontro e por ter uma funda74 mentação baseada nas teorias e práticas psicanalíticas.
Esse procedimento foi desenvolvido por Aiello-Vaisberg (1999) como mediador de experiências emocionais e facilitador da comunicação de elementos não conscientes das condutas humanas. A proposição desse procedimento teve sua inspiração no procedimento desenhos-estórias de Trinca (1997), mas difere-se deste na medida em que não se apresenta como um procedimento diagnóstico, mas como procedimento apresentativo-expressivo (Aiello-Vaisberg et al., 2005). Durante as entrevistas, os participantes foram convidados a desenhar e, posteriormente, a realizar uma estória sobre o desenho. O tema escolhido para essa ocasião foi elaborado com a intenção de favorecer ao participante a expressão de seu substrato afetivo-emocional, de suas ideias e de seus sentimentos acerca do tema de interesse da presente pesquisa. Para tanto, o tema trazia notícias sobre o assunto que se queria pesquisar, mas encontrava-se o mais possivelmente aberto, distanciado e não muito delimitado, para que fosse efetivamente um procedimento no qual o participante pudesse, ao mesmo tempo, expressar sua singularidade - comunicando os aspectos não conscientes relacionados ao tema proposto -, mas que também pudesse servir de material para a pesquisa. Nesse sentido, escolhemos o tema: "Uma situação de difícil manejo na sua prática profissional".

O pesquisador, no momento da entrevista, convidava o participante a fazer um desenho e, posteriormente à sua realização, pedia que fosse confeccionada uma estória sobre o desenho; por fim, finalizava-se a produção com a criação de um título. Foram disponibilizadas folhas de papel brancas e coloridas, lápis de diversas cores e canetas.

As informações obtidas nas entrevistas foram trabalhadas conforme proposto por Aiello-Vaisberg (1999). Partiu-se da livre inspeção do material, voltada à construção compreensiva e interpretativa, visando a captar sua contribuição individual na subjetividade grupal, ou seja, o sujeito coletivo, sua experiência como membro da subjetividade transindividual, médico da reprodução assistida.

\section{Resultados}

Os participantes aceitaram, sem resistência, participar do estudo. Todos perguntaram quanto tempo 
levaria e pareciam esperar algo de caráter objetivo, pois queriam saber mais quanto à natureza do que iriam fazer, se haveria um questionário, por exemplo. Aparentemente, esperavam algo conhecido de suas vivências também como pesquisadores, inseridos em outro contexto metodológico, tal como um questionário padronizado.

Quando da apresentação da proposta e do pedido que desenhassem, exclamaram surpresos: "um desenho!" Ao saberem do tema, alguns hesitaram por instantes e logo começaram a desenhar, outros hesitaram por um ou mais minutos. Alguns exploraram o que estava sendo apresentado como material (as canetas, os lápis coloridos), outros decidiram, muito rapidamente, pela folha branca e o lápis preto.

Todos os participantes, após a solicitação de contarem uma estória sobre o desenho que haviam feito, começaram a falar diretamente de suas próprias dificuldades e angústias diante dos atendimentos. Desenharam situações que já haviam vivenciado. Não eram histórias fictícias, mas, sim, situações de fato vividas. Ao mesmo tempo que diziam que eram situações difíceis, houve rapidez e desembaraço ao falarem de aspectos que consideravam de difícil manejo.

Os participantes apresentaram certa perplexidade diante de seus próprios desenhos. Com expressões faciais de surpresa, contemplavam seus desenhos em meio a breves momentos de silêncio. As situações de difícil manejo apresentadas mostraram-se relacionadas àquelas que ficavam impossibilitadas de solução segundo o saber técnico-científico. O tema principal foi o resultado negativo (teste de gravidez negativo).

Sessenta e oito por cento dos participantes falaram sobre esse mesmo assunto. Foram selecionados três desenhos-estórias para exemplificar os achados. Nomes fictícios foram dados aos participantes a fim de preservar suas identidades: Alejandro, James e Fred.

\section{Alejandro}

Desenho. Fez um desenho relativamente pequeno, na posição vertical do papel, no centro e à esquerda da parte superior da folha de sulfite branca. Havia uma mesa; de um lado, duas pessoas em pé chorando, uma olhando para a outra, e, do outro, uma pessoa em pé, de gravata, com um rosto em branco, no qual foi desenhada qualquer expressão. Segundo o participante, de um lado era o médico e, do outro, um casal chorando por ter recebido do médico um resultado de gravidez negativo. Logo abaixo desse desenho, um coração partido, com o tamanho proporcional à totalidade do primeiro desenho.

Estória. "É uma situação muito comum na clínica: lidar com um resultado negativo. Dar o diagnóstico não incomoda, o que incomoda é fazer o procedimento e tero resultado negativo. Como expressar e como lidar com o coração partido? Me sinto na obrigação de falar alguma coisa. Eu sofro com isso, e as pessoas veem que eu estou sofrendo junto. Não me incomodo com o índice de falha, não sou eu que estou fazendo errado. Não sou eu que falhei. O problema é lidar com o sofrimento deles. Quando eu estiver mais velho, não sei se vou aguentar. Quando o casal não engravida, é muito triste. Houve situações em que eu me emocionei junto com eles. Os pacientes gostam da empatia, gostam dessa proximidade, oproblema équeeles vão embora, parecem bem, mas eu fico muito angustiado; se sentem atémelhor, mas, quando vão embora, sou eu que fico mal. E, sabe, se a gente fala, tiram sarro e tal... Seilá, às vezes fico pensando se pode ser um tipo de vaidade querer que a paciente engravide... Seria bom se a gente tivesse um espaço para falar dessas coisas. Eu converso às vezes com um amigo médico, com a minha esposa, mas não é a mesmacoisa".

Título: Coração partido.

\section{James}

Desenho. O desenho foi feito no centro, com o papel na posição horizontal, tomando praticamente toda a folha de sulfite branca, com sua maior parte ocupando o lado direito superior e inferior. Há nele um homem sentado à mesa, com as mãos fechadas e com os braços em cima da mesa, onde estão organizados quatro montes de folhas; há um telefone do lado esquerdo. Do outro lado da mesa, vê-se um casal, desenhado de tamanho duas vezes maior que o homem que está do outro lado da mesa. A expressão facial da mulher sugere tristeza, e a do homem, perplexidade. Segundo o participante, o homem que está em um dos lados da mesa é o médico, e o casal do outro lado são os seus pacientes. 
Estória. "É o desenho de uma situação difícil em reprodução. É a situação de contar coisas tristes, de ter que usar métodos que o casal não queira. Ela está chorando... Eu acho difícil lidar com as emoções, em todas as esferas. Mas como profissional eu sou objetivo. Quanto mais velho eu fico, mais objetivo, falo tudo o que tenho que falar a respeito do tratamento, não engano ninguém. Às vezes eu digo que a chanceéde 1\% de gravidez, mas eles querem tentar, daí eu faço; senão, eles vão para o médico ao lado. Como na minha fantasia eu sou melhor do que o médico ao lado, eu faço... É muito difícil quando dá negativo. Eu não seise vocêsabe, mas eu preferiria passar para o psicólogo dar essa notícia. Falar: 'vai ali, tem um profissional que vai conversar com você que sabe lidar melhor com as emoções.' Queria dar a notícia positiva, e negativa encaminhar para o psicólogo. Não queria lidar com a emoção do negativo".

Título: Os problemas da fertilidade.

\section{Fred}

Desenho. Um desenho relativamente pequeno, feito na posição horizontal do papel, ao centro e à esquerda da folha de sulfite branca. É o desenho de uma mulher deitada sozinha com um leve sorriso, passando por um procedimento médico feito aparentemente por imagem. A mulher tem um corpo desenhado de maneira transparente, no qual se pode ver a parte interna de suas mamas, útero e ovários. Apresenta uma flecha 'saindo do ovário' esquerdo e que aponta para uma imagem não identificada.

Estória. "Uma mulher que não tem mais a capacidade reprodutiva própria, ela tem 44 anos. Ela não sabia, atéentão, não tinha sido informada. Quem informou? No caso, eu. Foi uma falha minha não ter informado, é uma falha da classemédica. Ninguém informou paraessa mulher que, depois dos 35 anos, a chance de engravidar diminuiria. Édifícil, porque éuma notícia negativa. Você sela, fecha a porta. Vocêestáalipara ajudaras pessoase, nessecaso, você é o porta-voz da notícia negativa. A nossa profissão é extremamente técnica, nós trabalhamos com possibilidades, e é obrigação do médico orientar e informar a paciente. Porque a pessoa vaiao médico? Para engravidar! Éisso que o casal quer. Quer alguém que explique paraeles as coisas, sobre os procedimentos. Eles vão buscar respostas evocêtem que estar pronto para isso. Os pacientes estão interessados no resultado. Não sou cruel nem pego no colo... . O paciente de hoje quer alguém técnico, não quer um médico com atitude de floreamento, que não resolva o problema, quer alguém com atitude".

Título: Desinformação.

\section{Discussão}

Em um primeiro momento, pareceu que pudesse ser mais fácil que os participantes se comunicassem de forma mais estruturada, a partir de referenciais pré-estabelecidos. As angústias relacionadas à sua prática profissional começaram a aparecer, sugerindo uma ligação com questões realmente difíceis ou mesmo desconhecidas ou não pensadas, devido ao fato de pressuporem algo que pudesse dar um delineamento claro para falarem do assunto, algo como um questionário.

Após a surpresa do pedido do desenho, foi curiosa a facilidade observada em falar de situações consideradas difíceis. Pode-se pensar em uma demanda muda, que talvez estivesse esperando um lugar suficientemente adequado para ser dita. Isso reforça a ideia de que o procedimento apresentativo-expressivo, que tem como característica o contato inter-humano, aliado ao ambiente de holding, pode facilitar a expressão das emoções. Deve ficar claro que esse tipo de intervenção, holding, não pode ser apreendido a partir da análise de comportamentos, mas, sim, mediante todas as ações do psicanalista no sentido da superação das dissociações, da constituição e do fortalecimento do self. O terapeuta pode intervir por meio de questionamentos que tragam reflexão sobre um tema e até mediar a criação de novas possibilidades de ação em relação ao assunto que está sendo tratado, como também pode ouvir e ajudar a sustentar sua experiência a fim de dar continência ao que for vivenciado (Winnicott, 1984).

Das situações difíceis, foi possível observar a vivência dos sentimentos que emergem na relação médico-paciente diante de um resultado negativo, como fica claro na fala de Alejandro quando faz referência à tristeza, à angústia e ao estado emocional desgastante que a experiência do exame negativo proporciona. Se o médico "deve" saber controlar seus 
sentimentos (Rocco, 1992), pode não ser abordada a relação médico-paciente que poderia trazer reflexões e saídas menos dissociadas.

Já Fred pôde demonstrar que existe também uma tendência ao distanciamento na relação com os pacientes por meio do discurso técnico. Ficou clara a tentativa de manter distância de suas próprias vivências emocionais, bem como das experiências emocionais dos pacientes. Como aponta a literatura, tal conduta pode ter sido sugestionada pelo modelo de formação na escola de medicina e pelo "aprendizado", com os mais experientes, de como ser um bom médico, repetindo defesas semelhantes a dos mais experientes, pautadas na explicação pela via da técnica, no organicismo (Bastos \& Proença, 2000; Ramos-Cerqueira \& Lima, 2002).

Como no estudo de Micelli-Baptista (2003), ficou claro que, no imaginário coletivo dos médicos entrevistados, existem medo e dúvida em relação às questões humanas que fogem ao conhecimento e à tecnologia médico-científica. James disse achar difícil lidar com as emoções e que, se fosse possível, preferiria que o psicólogo desse a notícia do resultado negativo de gravidez. Já Alejandro se pergunta como expressar e como lidar com o coração partido. Fred denuncia essa dificuldade ao enfatizar que a profissão do médico é extremamente técnica, como se, na medicina, não fosse tão importante contemplar os aspectos da subjetividade dos indivíduos.

Outro fator importante é que parece existir uma necessidade em responder à demanda do paciente, o que pode estar relacionado com a suposição de a figura do médico ter o saber sobre o outro (Trindade \& Emuno, 2002). A respeito do resultado negativo e/ou de uma notícia negativa parecer tão intrigante e angustiante, pode-se inferir uma associação a uma mensagem latente: a grande dificuldade de se admitir que, até mesmo para a medicina, existe um limite.

Como explicar o fato de um procedimento feito corretamente ter o resultado do exame de gravidez negativo? Balint (1975) afirma que todas as questões passam a ser incluídas no campo da medicina, pois o médico estaria caracterizado como "professor" dos pacientes, como "mago" das dificuldades humanas. Possivelmente, por essa razão, o fato de não se ter controle sobre todas as variáveis, especialmente no procedimento de reprodução assistida, apresentou-se como algo perturbador.
Setenta e sete por cento dos participantes mencionaram sentir a necessidade de espaços de reflexão, momentos para discutir as repercussões afetivas relacionadas ao trabalho, tal como Alejandro apresentou claramente. Porém, quando eles cogitaram essa possibilidade, pareceram constrangidos com a dúvida sobre a funcionalidade de uma organização formal que facilitasse a ocorrência de tal espaço.

Demonstravam-se interessados e temerosos ao mesmo tempo, como se percebessem que as entrevistas das quais estavam participando poderiam trazer aproximações com seus próprios sentimentos e um cuidado emocional, o que poderia ajudar o fazer profissional. Entretanto, o temor poderia relacionar-se não só ao fato de poderem sofrer comentários desagradáveis por parte dos colegas médicos, mas à sua atitude perante o que aconteceria e mesmo sobre a natureza das emoções despertadas. As reflexões de James, que preferiria deixar assuntos difíceis para um psicólogo; a preocupação de Fred de resolver o problema; os comentários de Alejandro em como lidar com o coração partido - talvez dele próprio -, e a necessidade de um espaço de escuta demonstram essa preocupação possivelmente latente. A proposição de um espaço lúdico e profissional pode contribuir para facilitar a expressão emocional de grupos com características semelhantes à da população estudada.

A partir deste estudo, pode-se sugerir a criação de espaços suficientemente acolhedores que facilitem a expressão emocional, para a manifestação do gesto espontâneo, visando à saúde emocional dos médicos. A partir do presente trabalho, fica claro que se faz importante a presença de um profissional psicólogo na equipe de reprodução assistida para servir de facilitador nas reflexões a cerca da subjetividade que emerge nesse tipo de ambiente para exercer uma atenção psicoprofilática (Bleger, 1984) em um espaço facilitador das comunicações emocionais profundas, do acolhimento, do gesto espontâneo.

Ampliar o conhecimento a respeito da experiência emocional do profissional médico especialista em reprodução assistida é importante para que haja possibilidade de refletir a respeito do fazer médico, que confronta diariamente com o sofrimento humano, para que esse profissional possa criar ou encontrar (Winnicott, 1984) possibilidades para viver sua experiência como 
médico e surpreender-se com o que encontra, sem a necessidade de defender-se ou afastar-se emocionalmente dos encontros com seus pacientes. Esse elemento de aproximação afetiva é importante, uma vez que se relaciona à saúde emocional, à gestualidade espontânea, elementos que, para Winnicott (1984), apontam para a saúde mental.

\section{Considerações Finais}

Tanto teoricamente quanto de acordo com a experiência clínica, vê-se que não só a relação médico-paciente, como a relação do próprio médico com sua experiência, configura uma situação delicada. Toda essa problemática foi evidenciada na medida em que foi possível a expressão das emoções sobre situações que são consideradas de difícil manejo.

No presente estudo, notou-se que os médicos demonstraram perplexidade quando perceberam elementos emocionais ativos e contundentes presentes em suas experiências clínicas. Foi possível compreender que tais aspectos podem encontrar-se, de certa forma, dissociados, e ocasionar sofrimento emocional.

A partir das entrevistas realizadas, compreendese que esse grupo de médicos localiza a situação de difícil manejo relacionada aos resultados clínicos não-esperados, depois de realizadas as intervenções técnicas. Nesse sentido, não ser capaz de "engravidar" uma paciente, mesmo contando com instrumentos, técnicas e conhecimento científico de excelência, gera espanto e poderia ser causador de ansiedade.

A partir do presente estudo, foi possível perceber a necessidade de se pensar a respeito de um modelo de formação médica que contemple de maneira interessante a subjetividade do médico, que, talvez, venha sendo sufocada pela importante, mas parcial, exigência com a técnica científica, o que pode levar a um quadro de sofrimento e de adoecimento emocional do médico.

Ficou caracterizada uma ação psicoprofilática na medida em que o auxílio psicológico foi ao encontro da população em situação que inspirava cuidados, promovendo um espaço de continência ao sofrimento do médico especialista em reprodução assistida. Por meio da intervenção psicanalítica feita pelo procedimento 78 apresentativo-expressivo, houve a possibilidade de uma experiência reflexivo-emocional a respeito de situações de difícil abordagem, propiciando uma possível vinculação verdadeira, produtiva, criativa e transformadora do real (Aiello-Vaisberg \& Machado, 1996).

\section{Referências}

Abram, J. (1996). A linguagem de Winnicott, dicionário das palavrase expressõesutilizadas porDonald W. Winnicott. Rio de Janeiro: Revinter.

Ambrosio, F. F. (2005). Ser e fazer - arte de papel: uma oficina inclusiva. Dissertação de Mestrado não-publicada, Departamento de Psicologia Clínica, Universidade de São Paulo.

Aiello-Vaisberg T. M. J. (1995). O uso de procedimentos projetivos na pesquisa de representações sociais : projeção e transicionalidade. Psicologia USP, 6 (2), 103127.

Aiello-Vaisberg T. M. J. (1999). Encontro com a loucura: transicionalidade e ensino de psicopatologia. Tese de livre docência não-publicada, Instituto de Psicologia, Universidade de São Paulo.

Aiello-Vaisberg T. M. J. (2004). Ser e fazer: enquadres diferenciados na clínica winnicottiana. São Paulo: Idéias e Letras.

Aiello-Vaisberg T. M. J. Corrêa, Y. B., \& Ambrosio, F. F. (2005). Encontros brincantes: o uso de procedimentos apresentativo-expressivos na pesquisa e na clínica winnicottiana. In T. M. J. Aiello-Vaisberg, Y. B. Correa \& F. F. Ambrosio. Cadernos ser e fazer: reflexões éticas na clínica contemporânea (pp.55-67). São Paulo: USP.

Aiello-Vaisberg T. M. J., \& Machado, M. C. L. (1996). Trasicionalidade e ensino de psicopatologia: pensando "aulas práticas" com Winnicott. In I. F. M. Catafesta (Org.), D. W. Winnicott na Universidade de São Paulo: o verdadeiro e o falso, a tradição independente na psicanálise contemporânea (pp. 239-252). São Paulo: Lemos.

Balint, M. (1975). O médico, seu paciente e a doença. Rio de Janeiro: Atheneu.

Bastos, L. A. M., \& Proença, M. A. (2000). A prática anatômica e a formação médica. Recursos Humanos, 7 (6), 395-402.

Bleger, J. (1984). Psico-higiene e psicologia institucional. Porto Alegre: Artes Médicas.

Gorayeb, R., Borsari, A. C. T., Gomes, A. C. R., Romão, A. P. M. S., \& Shuhama, R. (2009). Caracterização clínica e psicossocial da clientela de um ambulatório de esterilidade. Estudos de Psicologia (Campinas), 26 (3), 287-296. doi: 10.1590/S0103-166X2009000300002.

Lechner, L., Bolman, C., \& van Dalen, A. (2006). Definite involuntary childlessness: associations between coping, social support and psychological distress. Human Reproduction, 22 (1), 288-294.

Machado, M. C. L., \& Aiello-Vaisberg, T. M. J. (2003). Sofrimento, sentido e absurdo: ilusão criativa e ação sobre o 
mundo. In T. M. J. Aiello-Vaisberg \& F. F. Ambrosio (Orgs.), Trajetos do sofrimento: rupturas e (re) criações de sentido (pp.40-54). São Paulo: USP.

Mencarelli, V. L., \& Aiello-Vaisberg, T. M. J. (2005). Iluminando o self: uma experiência clínica psicanalítica não convencional. Estudos de Psicologia (Campinas), 22 (4), 415-423. doi: 10.1590/S0103-166X2005000400009.

Micelli-Baptista, A. (2003). Consulta psicoprofilática ao residente de medicina: proposta de um enquadre diferenciado àluz da perspectiva winnicotiana. Dissertação de mestrado nãopublicada, Departamento de Psicologia Clínica, Universidade de São Paulo.

Piccinini, C. A., Levandowski, D. C., Gomes, A. G., Lindenmeyer, D., \& Lopes, R. S. (2009). Expectativas e sentimentos de pais em relação ao bebê durante a gestação. Estudos de Psicologia (Campinas), 26 (3), 373-382. doi: 10.1590/S0 103-166X2009000300010

Ramos-Cerqueira, A. T. A., \& Lima, M. C. (2002). A formação da identidade do médico: implicações para o ensino de graduação em Medicina. Interface: Comunicação, Saúde, Educação, 6 (11), 107-16.

Rocco, R.P. (1992). Relação estudante de medicina-paciente. In J. Mello Filho (Org.), Psicossomática hoje (pp.45-46). Porto Alegre: Artes Médicas.
Rodriguez, C. A., \& Neto, P. P., \& Behrens, M. A. (2004). Paradigmas educacionais e a formação médica. Revista Brasileira de Educação Médica, 28 (3), 234-241.

Silva, M. R., \& Piccinni, C. A. (2007). Sentimentos sobre a paternidade e o envolvimento paterno: um estudo qualitativo. Estudos de Psicologia (Campinas), 24 (4), 561-573. 10.1590/S0103-166X2007000400015.

Trinca W. (Org.). (1997). Formas de investigação clínica em psicologia. São Paulo: Vetor.

Trindade Z. A., \& Enumo S. R. F. (2002). Triste e incompleta: uma visão feminina da mulher infértil. Psicologia USP, 13 (2), 151-182.

Verhaak, C. M., Smeenk, J. M. J., Evers, A. W. M., Kremer, J. A. M., Kraaimaat, F. W., \& Braat, D. D. M. (2007). Women's emotional adjustment to IVF: a systematic review of 25 years of research. Human Reproduction, 13 (1), 27-36.

Winnicott D. W. (1983). Os objetivos do tratamento psicanalítico. In D. W. Winnicott. O ambiente e os processos de maturação. Porto Alegre: Artes Médicas.

Winnicott, D. W. (1984). Consultas terapêuticas em psiquiatria infantil. Rio de Janeiro: Imago.

Recebido em: 13/1/2010

Versão final reapresentada em: 25/10/2010

Aprovado em: 7/6/2011 
